\title{
Recommendations for the surveillance of cancer-related fatigue in childhood, adolescent, and young adult cancer survivors: a report from the International Late Effects of Childhood Cancer Guideline Harmonization Group
}

\author{
Salome Christen ${ }^{1}$ (D) $\cdot$ Katharina Roser ${ }^{1}$ (D) - Renée L. Mulder ${ }^{2} \cdot$ Anica llic $^{1} \cdot$ Hanne C. Lie $^{3}$ (D) $\cdot$ Jacqueline J. Loonen $^{4}$ (D) \\ Anneli V. Mellblom ${ }^{3} \cdot$ Leontien C. M. Kremer ${ }^{2} \cdot$ Melissa M. Hudson $^{5}$ (D) Louis S. Constine $^{6} \cdot$ Roderick Skinner $^{7}$ (D) \\ Katrin Scheinemann $^{8,9,10}$. Jordan Gilleland Marchak ${ }^{11,12}$. Gisela Michel ${ }^{1}$ (i) - on behalf of the IGHG psychological late \\ effects group
}

Received: 18 March 2020 / Accepted: 3 June 2020 / Published online: 25 August 2020

(C) The Author(s) 2020

\begin{abstract}
Purpose Cancer-related fatigue (CRF) negatively affects the lives of childhood, adolescent, and young adult (CAYA) cancer survivors. We aimed to provide an evidence-based clinical practice guideline (CPG) with internationally harmonized CRF surveillance recommendations for CAYA cancer survivors diagnosed $<30$ years.

Methods This CPG was developed by a multidisciplinary panel under the umbrella of the International Late Effects of Childhood Cancer Guideline Harmonization Group. After evaluating concordances and discordances of four existing CPGs, we performed systematic literature searches. We screened articles for eligibility, assessed quality, extracted, and summarized the data from included articles. We formulated recommendations based on the evidence and clinical judgment.

Results Of 3647 articles identified, 70 articles from 14 countries were included. The prevalence of CRF in CAYA cancer survivors ranged from 10-85\%. We recommend that healthcare providers are aware of the risk of CRF, implement regular screening with validated measures, and recommend effective interventions to fatigued survivors.

Conclusions A considerable proportion of CAYA cancer survivors suffers from CRF even years after the end of treatment. Implications for Cancer Survivors We recommend that healthcare providers adopt regular screening to detect and treat CRF early and positively influence survivors' health and quality of life.
\end{abstract}

Keywords Survivors $\cdot$ Childhood, adolescent, and young adult cancer $\cdot$ Surveillance $\cdot$ Late effects $\cdot$ Cancer-related fatigue $\cdot$ Evidence-based guidelines

Salome Christen and Katharina Roser shared first authors

Katrin Scheinemann, Jordan Gilleland Marchak, and Gisela Michel shared last authors

Electronic supplementary material The online version of this article (https://doi.org/10.1007/s11764-020-00904-9) contains supplementary material, which is available to authorized users.

Gisela Michel

gisela.michel@unilu.ch

Extended author information available on the last page of the article

\section{Introduction}

Thanks to advances in treatment, long-term survival of childhood, adolescent, and young adult (CAYA) cancers has improved remarkably over the past decades [1-3]. As a result, the population of CAYA cancer survivors is increasing [4]. However, most survivors experience late effects from cancer and its treatment, such as cardiovascular disease, renal dysfunction, endocrinopathies, impaired cognitive function, poor mental health, and musculoskeletal problems [4-7].

Cancer-related fatigue is a well-known problem during the active treatment phase of cancer but can also be a frequent problem for survivors many years after completion of therapy $[8,9]$. The National Comprehensive Cancer Network of the 
USA defined cancer-related fatigue as "a distressing, persistent, subjective sense of physical, emotional and/or cognitive tiredness or exhaustion related to cancer or cancer treatment that is not proportional to recent activity and interferes with usual functioning" [10]. In survivors of adult cancers, about $30 \%$ experience cancer-related fatigue even years after completion of treatment $[11,12]$. For CAYA cancer survivors, the literature on the prevalence of cancer-related fatigue (hereafter referred to as fatigue) is contradictory. A number of studies have reported a high prevalence of fatigue in CAYA cancer survivors [13-15], but other studies have observed prevalence rates or fatigue levels comparable to controls [16, 17]. Fatigue has a negative impact on many aspects of CAYA cancer survivors' lives, such as personal relationships, school or work, and activities of daily life, and is associated with lower selfreported quality of life $[9,14,18]$.

Clinical practice guidelines (CPG) could help improve consistency of care, evidence-based healthcare delivery, and thus health outcomes and quality of life in survivors $[19,20]$. This is especially important as, to date, long-term follow-up (LTFU) for CAYA cancer survivors is not always well organized and few pediatric oncology institutions offer LTFU to adult survivors of CAYA cancers [21]. As many CAYA cancer survivors are followed by healthcare providers outside the pediatric oncology setting [22], CPGs can help to inform healthcare providers, as well as survivors, about cancer- and treatment-related risks such as fatigue.

In survivors of adult cancers, regular screening for fatigue is recommended [23, 24]. For CAYA cancer survivors, different groups in North America and Europe have developed LTFU CPGs to promote early detection of potential late effects [25-28]. However, these guidelines were developed independently and differ regarding their recommendations. This can cause uncertainty about which CPG to use in clinical practice and could impede the implementation of a CPG for LTFU of CAYA cancer survivors. Therefore, the International Late Effects of Childhood Cancer Guideline Harmonization Group (IGHG) was founded to harmonize CPGs for CAYA cancer survivors [29]. As the psychological late effects group of the IGHG, we aimed to harmonize the recommendations for fatigue surveillance in CAYA cancer survivors diagnosed before the age of 30 .

\section{Methods}

To develop this CPG, we utilized the international guideline harmonization methodology previously described in detail by Kremer et al. [29]. A multidisciplinary international group of 14 experts in pediatric oncology, radiation oncology, psychology, physiotherapy, epidemiology, and guideline methodology prepared the fatigue surveillance recommendations. The final recommendations were discussed with a wider group of
23 additional experts from 10 countries and reviewed by four patient stakeholders (Table S3).

\section{Comparison of existing guidelines}

Our group of experts first evaluated concordances and discordances among the existing CPGs from the Children's Oncology Group (COG) [25], the Dutch Childhood Oncology Group (DCOG) [26], the Scottish Intercollegiate Guidelines Network (SIGN) [27], and the United Kingdom Children's Cancer Study Group Late Effects Group (UKCCLG) [28] regarding fatigue surveillance recommendations. In case of discordance between the CPGs, we formulated clinical questions to achieve consensus. The clinical questions addressed five key issues: (1) Who needs surveillance? (2) At what age or time from exposure should surveillance be performed? (3) At what frequency should surveillance be performed? (4) What surveillance modality should be used? and (5) What should be done when abnormalities are found?

\section{Search strategy and selection criteria}

Systematic literature searches in MEDLINE (through PubMed), Web of Science, PsycInfo, and Scopus were performed in February 2016 and the search in MEDLINE was updated in March 2019 to identify all available evidence. The search terms "childhood cancer", "survivors", "late effects", and "fatigue" with synonyms and variations were used to search the databases (detailed search strategies provided in Tables $\mathrm{S} 4 \mathrm{a}-\mathrm{S} 4 \mathrm{c}$ ). Additionally, all reference lists of included articles were hand searched (by SC). We included only papers on humans, published in English, and published between January 1990 and March 18, 2019. Studies published after March 18, 2019 were not included in this CPG. If there was no evidence available for CAYA cancer survivors, we carefully extrapolated evidence from survivors of adult cancers. This evidence was identified by using the same search strategy but by replacing the "childhood cancer" term with "cancer".

Two authors first independently screened titles and abstracts and excluded irrelevant articles (SC, KR, HCL, JJL, AVM, KS, and GM participated in the title/abstract screening). In a second step, two authors independently assessed the eligibility of the full-text articles (SC, KR, HCL, JJL, AVM, KS, and GM participated in the full-text screening). Inclusion criteria were (1) typical childhood, adolescent, or young adult cancer diagnosis; (2) $\geq 75 \%$ of study participants were $<30$ years at cancer diagnosis; (3) survivors $(\geq 50 \%$ of study participants were $\geq 2$ years from diagnosis); (4) sample size $\geq 20$ participants (detailed inclusion and exclusion criteria in Table S5). Throughout this manuscript, "survivor" is, therefore, 
defined as being at least 2 years since diagnosis. In case of a disagreement between the two authors, a third author helped finding consensus regarding inclusion or exclusion of the article (KS or GM). Next, we extracted relevant information of the articles into evidence tables. One article could address more than one clinical question. Corresponding authors were contacted in the event of missing primary data. We assessed the quality of the included articles by evidence-based methods provided by the Cochrane Childhood Cancer (Table S6). For every clinical question, we formulated and graded a conclusion of evidence based on an adapted version of the Grading of Recommendations Assessment Development and Evaluation criteria (GRADE; Table S7) [29, 30].

\section{Translating evidence into recommendations}

Recommendations were based on consideration of the evidence, costs, benefits versus harms of the surveillance intervention, the need to maintain the flexibility of application across different healthcare systems, and clinical judgment. Decisions were made through group discussion and consensus, and final recommendations were supported unanimously. The strength of the fatigue recommendations was graded according to published evidence-based methods (Table S8) [31]. The harmonized fatigue surveillance recommendations were discussed with a wider group of additional 23 experts (Table S3) from 10 countries via teleconference and critically appraised by four survivor representatives (Table S3) via electronic communications. We used the feedback from these discussions for the finalization of the recommendations. The recommendations will be updated within 5 years.

\section{Results}

Comparing the four existing surveillance recommendations for fatigue, we found they were discordant in all areas (Table S9). Based on the discordances, nine clinical questions were formulated to investigate the evidence in more detail (Table S10). The evidence tables (Table S11) and detailed conclusions of evidence (Table S12) are presented as Supplementary Material.

Of 3647 studies identified, 530 full texts were screened and 70 articles were eligible for the fatigue surveillance recommendations (Fig. S1), with a total sample of $n=11,628$ CAYA cancer survivors. One CPG and four systematic reviews were included. The 65 original studies were conducted in 14 different countries in Asia (12 studies), Europe (21 studies), North America (30 studies), and South America (two studies). The conclusions of evidence and the recommendations are presented in Tables 1 and 2.

\section{Who needs surveillance?}

\section{Evidence on the risk of fatigue}

The existing CPGs were discordant as only two specified the population at risk ("all survivors"), $[25,26]$ and only one surveillance recommendation identified risk factors for fatigue in CAYA cancer survivors (Table S9) [25].

There is evidence that CAYA cancer survivors are at risk for fatigue (level A; Table 1) [13-15, 17, 18, 32-54]. We found 28 articles (24 studies) that reported the prevalence of fatigue in CAYA cancer survivors (Table S2) [13-15, 17, 18, 32-54]. Prevalence of fatigue ranged from 10.2 to $85.0 \%$ over all 24 studies [13-15, 17, 18, 32-37, 39-41, 44-49, 51-54].

Some evidence suggests that there is an increased risk for fatigue in CAYA cancer survivors compared with controls (level C; Table 1) [13, 14, 17, 33, 39, 44]. Five studies found that the prevalence of fatigue is higher in survivors than controls with a difference ranging from 5 to $20 \%$ (two were statistically significant at $p<0.05$; Table S2) $[13,14,33,39,44]$. One study reported a lower prevalence of fatigue in survivors that was not significantly different from that of community norms [17].

Evidence suggests higher levels of fatigue in survivors of CAYA cancer compared with controls (level B; Table 1) [15, 16, 33, 36, 43, 44, 55-66]. Of 30 articles (29 studies) describing a level of fatigue in CAYA cancer survivors $[15,16,18,33,36,37,43,44,49,52,53$, 55-73], ten articles reported the level of fatigue in CAYA cancer survivors only $[18,37,49,52,53,68$, $69,71-73]$, one was a case-control study with nonfatigued survivors as controls [70], and one used survivors of adult cancers as controls [67]. The other 18 articles compared levels of fatigue in survivors with healthy controls (Table S2) $[15,16,33,36,43,44$, 55-66]. In twelve of these articles, survivors had statistically significant higher levels of fatigue compared with that of controls $[15,33,36,43,44,55,56,58,62$, 64-66], whereas two studies reported statistically significant lower levels of fatigue in survivors compared with controls [60,61], and four studies reported no statistical difference between groups [57, 59, 63] or conflicting evidence [16].

\section{Evidence on risk factors for fatigue}

One existing CPGs identified pulmonary radiation as a major risk factor for developing fatigue [25]. However, we identified no studies investigating the risk of fatigue after pulmonary radiation in CAYA cancer survivors. 
Table 1 Overall conclusions of the evidence

Who needs surveillance?

Prevalence of cancer-related fatigue (CRF) in childhood, adolescent and young adult (CAYA) cancer survivors [13-15, 17, 18, 32-54]

CAYA cancer survivors are at risk for CRF with prevalence ranging from 10 to $85 \%$

Increased risk for fatigue in CAYA cancer survivors vs. controls

There was a higher prevalence of CRF in survivors with a difference ranging from 5 to $20 \%$

Levels of CRF in CAYA cancer survivors [15, 16, 18, 33, 36, 37, 43, 44, 49, 52, 53, 55-73]

Higher levels of fatigue in CAYA cancer survivors vs. controls

Level B $[15,16,33,36,43,44,55-66]$

Risk factors for CRF in CAYA cancer survivors [13-18, 41, 42, 45, 50, 53, 60, 61, 68, 70, 73]

Treatment-related risk factors

Unclear risk after CNS/brain irradiation

Unknown risk after pulmonary radiation

Increased risk after radiotherapy (not further specified)

No significant effect of total body irradiation

No significant effect of chemotherapy

No significant effect of surgery

No significant effect of stem cell transplantation

No significant effect of duration of treatment

No significant effect of treatment era

Clinical risk factors

Increased risk in survivors with psychological distress

Increased risk in survivors with a relapse

Increased risk in survivors with late effects or health problems

Increased risk in survivors who experience pain

Increased risk in survivors with sleep problems

Increased risk in survivors with neuro-cognitive impairment

Increased risk in survivors with higher brain dysfunction

Increased risk in survivors with a heart problem

Increased risk in survivors with exercise-induced symptoms

Increased risk in survivors with lung fibrosis

Increased risk in survivors with higher BMI or obesity

Decreased risk in survivors with better health-related quality of life

Decreased risk with longer time since diagnosis

No significant effect of age at diagnosis

No significant effect of primary cancer diagnosis

No significant effect of thyroid status

No significant effect of amount of exercise

No significant effect of motility disturbance of limbs

No significant effect of seizures

No significant effect of ocular/vision impairment

No significant effect of endocrine abnormality

No significant effect of cytokine levels

No significant effect of smoking

No significant effect of happiness

Demographic risk factors

Increased risk with older age at follow-up

Increased risk in female survivors

Increased risk in unmarried survivors

Increased risk in survivors with children

Decreased risk in employed survivors

No significant effect of level of education, overall average grade and remedial education

No significant effect of household income

Conflicting evidence $[16,17,41,42$,

61]

No studies

Level C [15-17, 53, 60]

Level B [41, 61]

Level B $[15,17,41,53,60]$

Level B $[17,41]$

Level B [17, 60]

Level C [16]

Level C [13]

No significant effect of ethnicity

No significant effect of receiving social benefits

Level A [13, 15, 16, 50, 53, 70]

Level B $[17,18,45]$

Level B [16, 17, 50, 53, 60]

Level B [18, 42, 50, 70]

Level C [18, 70]

Level C [18]

Level C [68]

Level C [15, 42]

Level C [18]

Level C [15]

Level C [13, 15, 18, 42, 50, 53]

Level C [60]

Level C [16, 17, 53, 60, 61]

Level B [15-17]

Level B [13, 15-17, 42, 53, 60, 61]

Level B $[13,15]$

Level B [70, 73]

Level C [68]

Level C [68]

Level C [68]

Level C [68]

Level C [42]

Level C [42]

Level C [60]

Level B $[13,14,16,17,42,53,60$,

61]

Level C [13-17, 41, 42, 50, 53, 60, 61]

Level C [13-16, 18]

Level C $[15,18]$

Level B [14-16, 18, 50]

Level B [13, 14, 16, 60]

Level C [17]

Level C [17, 53]

Level C [14] 
Table 1 (continued)

\begin{tabular}{|ll|}
\hline At what frequency and for how long should surveillance be performed? \\
\hline Risk of CRF in CAYA cancer survivors[70, 73] & No studies \\
\hline Unknown latency time to develop CRF & No studies \\
\hline $\begin{array}{l}\text { Unknown predictors for change over time } \\
\begin{array}{l}\text { Risk of CRF does not change over time in the majority of survivors. } \\
\text { However, in some survivors the risk of CRF increases or decreases } \\
\text { over time. }\end{array}\end{array}$ & Level B [70, 73] \\
\hline
\end{tabular}

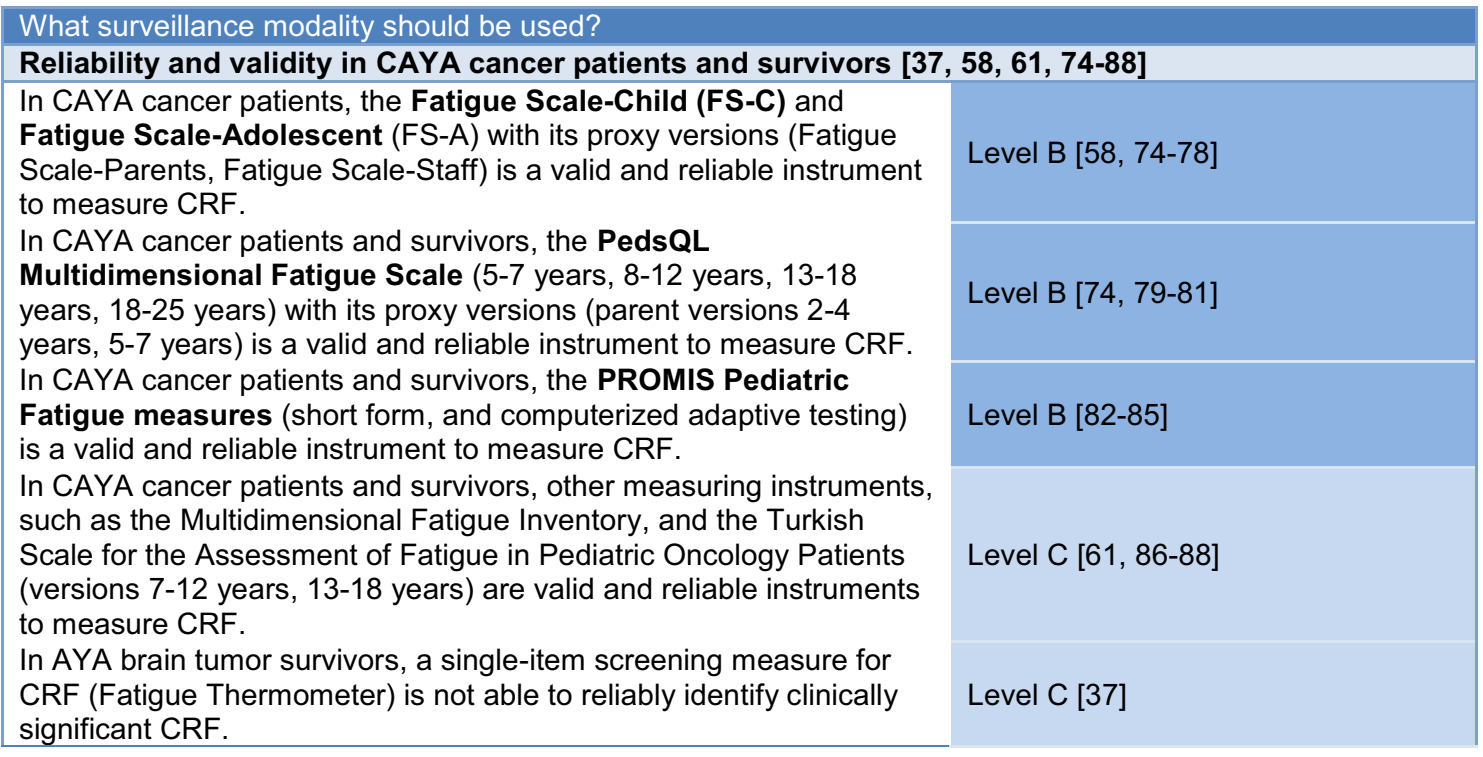

\begin{tabular}{|c|c|}
\hline \multicolumn{2}{|c|}{ Effectiveness of CRF interventions in CAYA cancer patients and survivors [36, 89-95] } \\
\hline $\begin{array}{l}\text { No studies reported on the effect of individual physiotherapy as an } \\
\text { intervention for CRF }\end{array}$ & No studies \\
\hline $\begin{array}{l}\text { No studies reported on the effect of a revalidation program as an } \\
\text { intervention for CRF }\end{array}$ & No studies \\
\hline Reduction in CRF after a physical activity intervention & $\begin{array}{l}\text { Level B, existing guideline }[36,92- \\
\text { 95] }\end{array}$ \\
\hline Reduction in CRF after an education intervention & Level B $[91,94]$ \\
\hline Reduction in CRF after a cognitive behavioral therapy intervention & Level C, existing guideline $[89,95]$ \\
\hline Reduction in CRF after an adventure-based training & Level C [90] \\
\hline Reduction in CRF after relaxation and mindfulness interventions & Level C, existing guideline $[92,95]$ \\
\hline $\begin{array}{l}\text { No significant effect of a combined physical activity plus psychosocial } \\
\text { intervention }\end{array}$ & Level C [92] \\
\hline $\begin{array}{l}\text { The evidence is insufficient about the usefulness and safety of } \\
\text { pharmacological interventions }\end{array}$ & Existing guideline [95] \\
\hline
\end{tabular}

We identified 16 studies that evaluated risk factors for fatigue in survivors of CAYA cancers [13-18, 41, 42, 45, 50, $53,60,61,68,70,73]$. The only treatment-related risk factor associated with an increased risk for fatigue was any radiotherapy (level C; Table 1) [15-17, 53, 60]. No significant associations were found between fatigue and the following treatment-related risk factors: total body irradiation [41, 61], chemotherapy $[15,17,41,53,60]$, surgery $[17,41]$, stem cell transplantation [17, 60] (all level B), duration of treatment [16], and treatment era [13] (both level C). 
Table 2 Surveillance recommendations for cancer-related fatigue in survivors of childhood, adolescent and young adult cancers (see Fig. 1 for process of CRF surveillance)

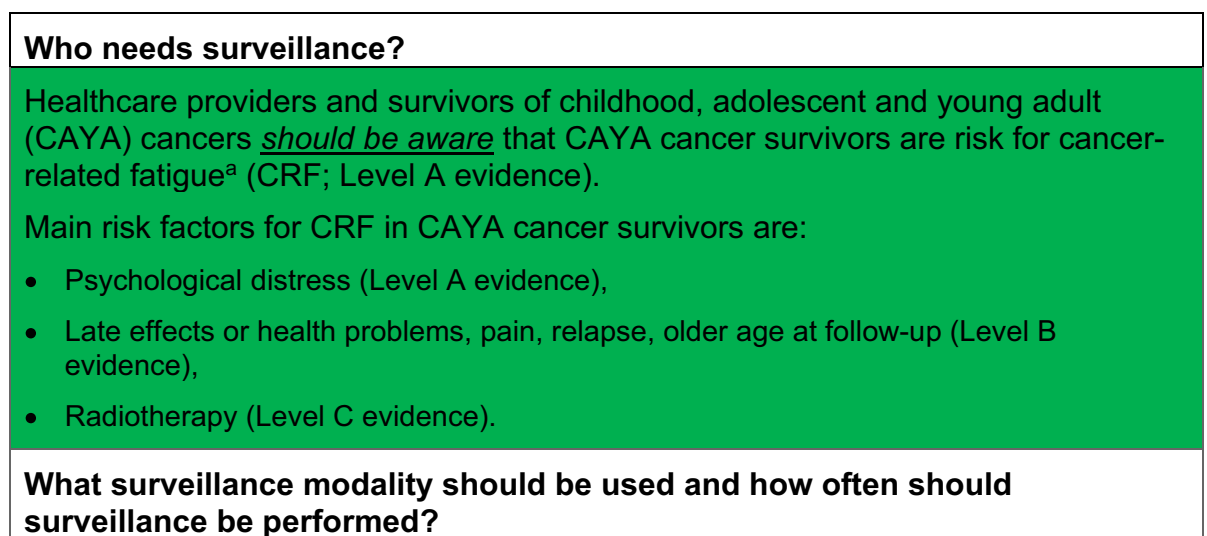
surveillance be performed?

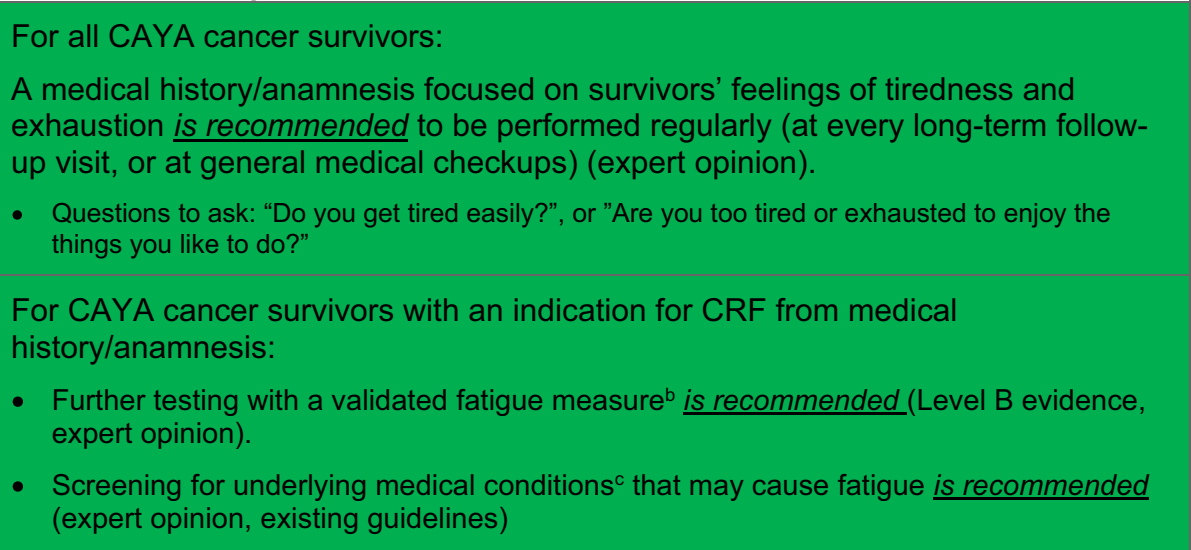

\section{What should be done if abnormalities are identified?}

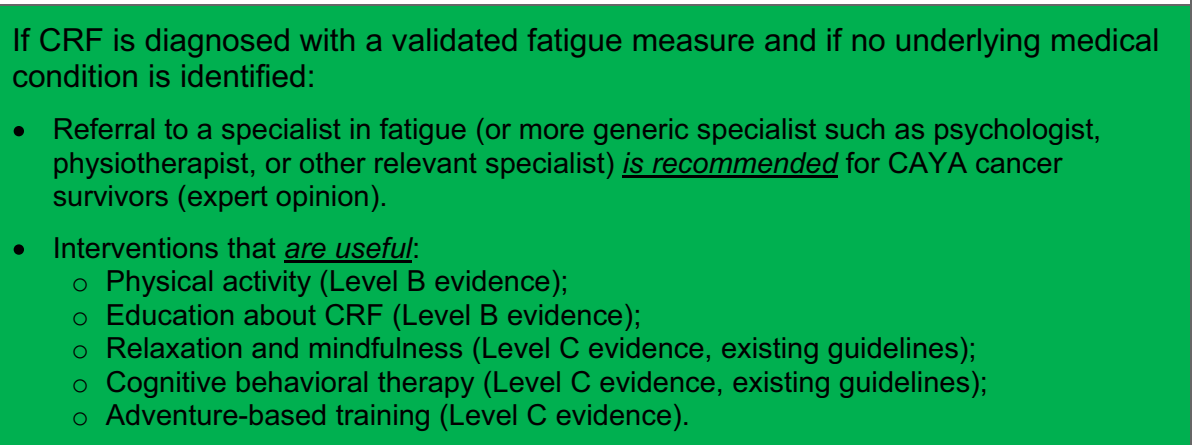

\footnotetext{
${ }^{a} \mathrm{CRF}$ is defined as "a distressing, persistent, subjective sense of physical, emotional, and/or cognitive tiredness or exhaustion related to cancer or cancer treatment that is not proportional to recent activity and interferes with usual functioning" [10].

${ }^{\mathrm{b}}$ Ideally the PROMIS Pediatric Fatigue measure (http://www.healthmeasures.net/index.php?Itemid=992 [accessed August 29th 2019]) or the PedsQL Multidimensional Fatigue Scale (https://eprovide.mapi-trust.org/instruments/pediatric-quality-of-life-inventory-multidimensional-fatigue-scale [accessed August 29th 2019]); see Table S13 for list of all measures validated in CAYA cancer patients and survivors

${ }^{c}$ e.g., other late effects like cardiac dysfunction, [96] endocrine dysfunction, pulmonary dysfunction, and renal dysfunction (IGHG guidelines under development); and/or other general causes like anemia, arthritis, neuromuscular complications, pain, fever and/or infection, and nutritional deficiencies $[24,97]$ (list not conclusive)
}

The following clinical risk factors were associated with an increased risk of fatigue: psychological distress (level A) [13, $15,16,50,53,70]$, a relapse $[17,18,45]$, late effects or health problems $[16,17,50,53,60]$, and pain $[18,42,50,70]$ (all level B). The following clinical risk factors were associated with a decreased risk of fatigue: longer time since diagnosis
$[16,17,53,60,61]$ and better health-related quality of life [60] (both level C). No significant associations were found between fatigue and the following clinical risk factors: age at diagnosis [15-17], primary cancer diagnosis [13, 15-17, 42, $53,60,61]$, thyroid status $[13,15]$, and amount of exercise $[70,73]$ (all level B). 
The following demographic risk factors were associated with an increased risk for fatigue: older age at follow-up (level B) $[13,14,16,17,42,53,60,61]$, female sex $[13-17,41,42$, $50,53,60,61]$, not being married/in a relationship [13-16, 18], and having children [15, 18] (all level C). Being employed was associated with a decreased risk for fatigue (level B) [14-16, 18, 50]. No significant associations were found between fatigue and the following demographic risk factors: level of education (level B) [13, 14, 16, 60], household income [17], ethnicity [17, 53], and receiving social benefits [14] (all level C).

\section{At what age or time from exposure should surveillance be performed?}

\section{Evidence on latency time}

The existing CPGs were discordant; only two specified when surveillance for fatigue should start (2 years after the end of treatment [25] or at the late effects outpatient clinic [26]). We found no studies that reported on the latency time to develop fatigue in survivors of CAYA cancers.

\section{At what frequency should surveillance be performed?}

\section{Evidence on change of risk over time}

The existing CPGs were discordant as only two specified the interval for fatigue surveillance (one recommends yearly surveillance [25], the other surveillance every 5 years [26]).

We identified two studies that reported unchanged risk for fatigue over time in the majority of CAYA cancer survivors but that fatigue status can change over time in some survivors (level B) $[70,73]$. One study showed that long-term survivors can be persistently fatigued or persistently non-fatigued but also that fatigue status can change over time: a median of 2.7 years after the first assessment, 39.6\% of former fatigue cases were no longer fatigued and $18.4 \%$ of former nonfatigue cases became fatigued [70]. The other study showed that mean levels of fatigue did not change significantly from end of treatment to 36 months post-therapy [73].

\section{What surveillance modality should be used?}

\section{Evidence on validity and reliability of fatigue measures}

Only one existing CPG specified a measure that should be used for fatigue surveillance [26]. More general surveillance recommendations (screen for an underlying medical condition, psychosocial assessment) were made by two existing CPGs [25, 26].

In our systematic search, we found 17 studies and one systematic review that assessed the psychometric properties of seven different measures for fatigue in CAYA cancer survivors [37, 58, 61, 74-88]. Ten studies measured fatigue in CAYA cancer patients [74, 76-80, 82, 83, 86, 87], five in CAYA cancer survivors $[37,61,81,84,88]$, and three in a mixed patient and survivor population [58, 75, 85]. Five studies and the systematic review investigated the Fatigue Scales (Fatigue Scale-Child, Fatigue Scale-Adolescent, and proxy versions) [58, 74-78], four studies the PROMIS Pediatric Fatigue Measures [82-85], three studies and the systematic review the PedsQL Multidimensional Fatigue Scale (Peds QL MFS) [74, 79-81], and five studies other measures (Fatigue Thermometer [37], Multidimensional Fatigue Inventory [88] Turkish Scale for the Assessment of Fatigue in Pediatric Oncology Patients [86, 87], and 12-item fatigue questionnaire [61]).

Evidence suggests that the Fatigue Scales, the PROMIS pediatric fatigue measures, and the PedsQL MFS are valid and reliable measures to diagnose fatigue in patients and survivors of CAYA cancers (level B; Table 1) [58, 74-85]. There is some evidence suggesting other measures, such as the Turkish Scale for the Assessment of Fatigue in Pediatric Oncology Patients and a 12-item fatigue questionnaire, are valid and reliable in measuring fatigue in patients and survivors of CAYA cancers (level C) [61,86-88]. One study found that a single-item screening measure for fatigue is not able to reliably identify clinically significant fatigue in CAYA brain tumor survivors (level C) [37]. A list of the fatigue measures validated in patients or survivors of CAYA cancers is provided in Table S13.

\section{What should be done when abnormalities are found?}

Only one existing surveillance recommendation specified possible interventions for fatigue in CAYA cancer survivors, namely individual cognitive therapy, a revalidation program, or individual physiotherapy [26].

We identified no studies reporting on a revalidation program or individual physiotherapy in the treatment of fatigue in CAYA cancer survivors. We found one study that investigated a cognitive-behavioral intervention in CAYA cancer survivors [89]. Two studies in CAYA cancer survivors [36, 90], one study in CAYA cancer patients [91], and three systematic reviews in CAYA cancer patients and survivors [92-94] investigated effects of other fatigue interventions. In addition, we identified one CPG on the management of fatigue among CAYA cancer patients [95].

Evidence suggests that physical activity interventions (e.g., aerobic, yoga, or combined) [36, 92-95] and education interventions lead to a reduction in fatigue in CAYA cancer survivors (both level B; Table 1). Some evidence suggests that adventure-based training (group activities including rock climbing and team building games) can improve fatigue in CAYA cancer survivors (level C) [90]. In addition, some 


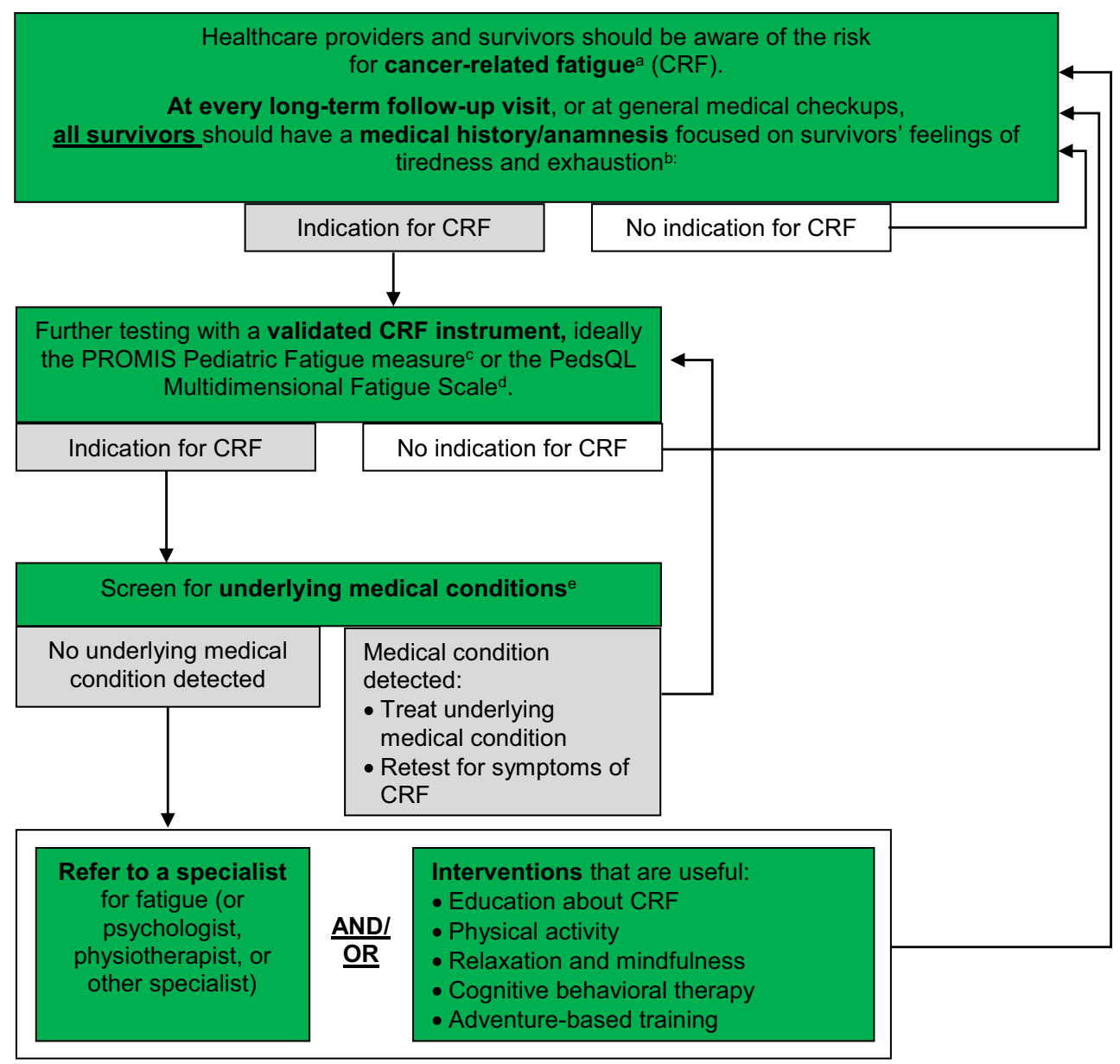

Fig. 1 Process of screening and interventions for cancer-related fatigue in survivors of childhood, adolescent, and young adult cancers. The green color indicates a strong recommendation to do. Superscript letter "a": cancer-related fatigue is defined as "a distressing, persistent, subjective sense of physical, emotional and/or cognitive tiredness or exhaustion related to cancer or cancer treatment that is not proportional to recent activity and interferes with usual functioning" [10]. Superscript letter "b": questions to ask: "Do you get tired easily?" or "Are you too tired or exhausted to enjoy the things you like to do?" Superscript letter "c":

evidence suggests that relaxation and mindfulness interventions (e.g., acupressure, massage, mindfulness) resulted in a reduction in fatigue (level C, existing guideline) $[92,95]$. To date, there is insufficient evidence about the usefulness and safety of pharmacological fatigue interventions in CAYA cancer patients and survivors (existing guidelines) [95].

\section{Translating evidence into recommendations}

Based on the evidence and group consensus, the panel recommends that healthcare providers and survivors should be aware of CAYA cancer survivors' risk for fatigue (strong recommendation based on level A evidence; Table 2). The main risk factors for fatigue in CAYA cancer survivors are psychological distress, late effects or health problems, pain,
http://www.healthmeasures.net/index.php?Itemid=992 [accessed July 1, 2019]. Superscript letter "d": https://eprovide.mapi-trust.org/instruments/ pediatric-quality-of-life-inventory-multidimensional-fatigue-scale [accessed July 1st 2019]. Superscript letter "e": e.g., other late effects like cardiac dysfunction, [96] endocrine dysfunction, pulmonary dysfunction, and renal dysfunction (IGHG guidelines under development); and/or other general causes like anemia, arthritis, neuromuscular complications, pain, fever and/or infection, and nutritional deficiencies $[24,97]$ (list not conclusive)

relapse, older age at follow-up, and radiotherapy (strong recommendation based on levels A-C evidence; Table 2).

Many CAYA cancer survivors are not in regular LTFU [98-100] but should be screened for fatigue nevertheless. If survivors are not in LTFU care, they should be screened for fatigue at general medical checkups. In the case of fatigue, screening is not expected to be overly burdensome for the survivors nor are false-positive screening results and subsequent examinations. However, screening for fatigue in the regular LTFU appointment, including potential false-positive screening results with subsequent examinations and referrals, could result in slightly higher costs of LTFU care. Based on the identification of a broad range of risk factors, the knowledge of the high prevalence and high levels of fatigue among CAYA cancer survivors, and the low burden for survivors, the expert panel decided to strongly recommend surveillance of 
fatigue for all survivors. Based on the uncertainty regarding the risk of fatigue over time, the panel recommends lifelong screening for fatigue.

Existing CPGs for fatigue surveillance in survivors of adult cancers recommend a two-step assessment: first, screen for fatigue with a numerical rating scale (NRS; 0-10 scale) and perform further assessment if NRS $\geq 4$ [24, 97]. The panel decided to use a similar approach, but not to use a one-item screening measure for fatigue, because it may not reliably identify clinically significant fatigue in survivors of CAYA cancers [37]. Therefore, we recommend that, for all CAYA cancer survivors, healthcare providers should perform a medical history/anamnesis focused on the survivor's feelings of tiredness and exhaustion at every regular long-term follow-up visit or at general medical checkups (strong recommendation based on expert opinion; Table 2). If there is an indication for the presence of fatigue, the panel recommends further testing with a validated fatigue measure, ideally with the PROMIS Pediatric Fatigue Measures or the PedsQL MFS (strong recommendation based on level B evidence and expert opinion; Table 2). A description of the surveillance process is presented in Fig. 1.

We based our screening recommendations on several considerations. First, the measure has to demonstrate validity and reliability in CAYA cancer patients or survivors. Second, extensive assessments may not be feasible to implement in clinical practice. Third, to be useful along the cancer survivorship trajectory of CAYA cancer survivors, it is important that the measure has versions for different age groups, including a version for adult survivors. Fourth, the measure needs to be readily available for healthcare providers. Fifth, the measure needs to be available in different languages because it will only be used when available in the country's language. The PROMIS Pediatric Fatigue Measure and the PedsQL MFS represent two assessment measures with these qualities (Table S13). Both measures are validated and demonstrate good psychometric properties, both have short versions (1018 items), versions for different age groups including adult survivors (PedsQL MFS-Young Adult and Adult; PROMIS Fatigue measure), are available online and free of cost for clinicians, and have been translated into various languages.

There is a spectrum of health problems that can cause fatigue symptoms (e.g., late effects such as cardiac dysfunction [96], endocrine dysfunction, pulmonary dysfunction, and renal dysfunction (IGHG guidelines under development); and/ or other health problems such as anemia, arthritis, neuromuscular complications, pain, fever and/or infection, and nutritional deficiencies) $[24,97]$. Therefore, if there is an indication for the presence of fatigue in a CAYA cancer survivor, the panel recommends to screen for underlying medical conditions (strong recommendation based expert opinion; Table 2).

If no underlying medical condition is identified, the referral of fatigued CAYA cancer survivors to a specialist in fatigue
Table 3 Gaps in knowledge and future directions for research

- High-quality research on risk of fatigue and risk factors for fatigue in CAYA cancer survivors using scientifically validated fatigue measurements (PROMIS Pediatric Fatigue, PedsQL Multidimensional Fatigue Scale)

- Longitudinal studies characterizing the course of fatigue in CAYA cancer patients and survivors and indicators for change

- Investigations of the impact of aging and elapsed time from diagnosis on risk for fatigue

- Investigations evaluating the risk for fatigue after CNS/brain irradiation

- Evaluation of the reliability and validity of a 1-item screening tool for fatigue in CAYA cancer survivors (mixed diagnoses) and parents of very young survivors

- Psychometric validation of fatigue measures in adult CAYA cancer survivors

- Determination of clinically significant thresholds for fatigue measures

- High-quality randomized controlled trials with larger samples to assess

the effectiveness of fatigue interventions in CAYA cancer survivors.

- Identify the most effective interventions for different age groups (pediatric survivors, adolescent survivors, young adult survivors, adult survivors of CAYA cancers)

- Test safety and effectiveness of pharmacological interventions to reduce fatigue in CAYA cancer survivors

$C A Y A$, childhood, adolescent, and young adult; $C N S$, central nervous system; PROMIS, Patient-Reported Outcome Measure Information System

(or a more generic specialist such as psychologist, physiotherapist, or another relevant specialist) is recommended (strong recommendation based on expert opinion; Table 2). Additionally, the panel recommends that all fatigued survivors should be provided with information about fatigue and strategies for the management of fatigue symptoms. Healthcare providers should also encourage survivors to engage in interventions that have been shown to be effective in reducing fatigue, such as physical activity and adventure-based training, relaxation and mindfulness interventions, and cognitive behavioral therapy (strong recommendation based on levels B and $\mathrm{C}$ evidence and existing guidelines; Table 2, Fig. 1).

\section{Discussion}

We summarize the harmonized recommendations for fatigue surveillance in CAYA cancer survivors diagnosed before the age of 30 years. The recommendations were developed using scientifically rigorous methods, are based on evidence from published literature, and are supplemented by expert opinion for topics with little or no evidence. The recommendations are intended to standardize and improve the quality of LTFU care for CAYA cancer survivors and to positively influence fatigue outcomes in survivors. The panel also aimed to raise awareness about CAYA cancer survivors' risk of fatigue among healthcare providers and CAYA cancer survivors and empower survivors to make informed health choices. 
We found that the prevalence of fatigue in survivors of CAYA cancers varied widely from 10 to $85 \%$. Several factors explain this variability. First, we included 28 studies from 14 different countries on three continents (America, Europe, and Asia) with different cultural backgrounds. Then, twelve of the 28 included studies used a tool for assessment of fatigue that was neither standardized nor validated. The other 16 studies used seven different measures to determine the prevalence of fatigue. Additionally, the populations of the included studies varied considerably regarding sample size, follow-up time, included primary diagnoses, and age at diagnosis. The use of so many different assessments for fatigue and heterogeneity in study populations likely contributed to the large differences in the prevalence of fatigue in CAYA cancer survivors.

Despite a sizable number of studies that reported risk factors for fatigue in CAYA cancer survivors, the level of evidence for the recommendations is mainly moderate to low. We found no studies that investigated the latency time to develop fatigue and only two studies that investigated the clinical course of fatigue in CAYA cancer survivors. Future studies should focus on high-quality research to investigate the risk of and risk factors for fatigue in CAYA cancer survivors using scientifically validated fatigue measures (preferably PROMIS Pediatric Fatigue Measure or PedsQL MFS) in CAYA cancer survivors and especially in older adult survivors of CAYA cancers. In addition, longitudinal assessment of fatigue in CAYA cancer patients and survivors is needed to identify the change of fatigue patterns over time (Table 3).

Thirteen different measures to assess fatigue were used in the included studies, and twelve studies used a nonstandardized measure. The use of 25 different measures makes a comparison of study results difficult. To increase comparability across studies, as well as to measure the quality of care across countries, we highly recommend that researchers and clinicians use the recommended fatigue measures unless they need a more specific measure to answer their research questions. This recommendation is in line with other research that has proposed that the PROMIS fatigue measures (child and adult versions) should be adopted as standard measures of fatigue impact and severity [101].

It would be useful to have a psychometrically sound but very brief fatigue assessment to assess fatigue as a secondary outcome and increase the standardization of fatigue surveillance in survivors (Fig. 1). This would reduce the burden associated with fatigue surveillance and potentially improve clinician adherence to fatigue surveillance recommendations. In this regard, the psychometric properties of the Fatigue Thermometer (a 1-item screening tool) [37] should be tested in diagnostic groups other than brain tumor survivors (Table 3). Other barriers for surveillance of fatigue include not all institutions have a LTFU program or not all survivors have access to a LTFU program, time constraints during the follow-up appointments, providers' lack of awareness that many CAYA cancer survivors suffer from fatigue, absence of highly effective treatments for fatigue, and previous contradictory evidence about the prevalence of fatigue in CAYA cancer survivors. Additionally, defining clinically meaningful thresholds for fatigue measures would be useful for clinical practice. Health problems such as fatigue, with unspecific and subjective symptoms, are difficult to measure objectively; validated clinically, significant thresholds are important to support health insurance coverage for interventions that remediate fatigue (Table 3).

When no underlying medical condition is identified, the panel recommends referring survivors who endorse fatigue to a specialist in fatigue (Fig. 1). However, not many countries have specialists for fatigue. Healthcare professionals might need to refer survivors to more generic specialists, such as psychologists or physiotherapists. If fatigue specialists are not available, healthcare professionals should counsel survivors about fatigue and interventions available to manage fatigue symptoms. Referral to a more generic specialist should be considered if the interventions are not successful in remediating fatigue, survivors find it difficult to adhere to the interventions, or need more support and guidance. Physical activity and adventure-based interventions should be appropriate for the survivor's age and physical abilities. Survivors with a higher risk of injury due to chronic health problems or deconditioning should be referred to a physiotherapist for supervised training to assure physical activity are safely implemented. Depending on the maturity and cognitive abilities, relaxation and mindfulness interventions can be useful. Cognitive-behavioral interventions need more resources than the more generic interventions but should be considered for severely fatigued survivors or if other interventions are not successful. Pharmacological approaches (erythropoietin, methylphenidate) should not be routinely used to manage fatigue in CAYA cancer patients and survivors [95] and use of supplements such as Paullinia cupana, ginseng products, or CoQ10 is not recommended in survivors of adult cancers because of limited effectiveness and evidence [24]. Supplements should therefore not be routinely used in CAYA cancer survivors.

To date, only a few studies have assessed the effectiveness of interventions for fatigue in CAYA cancer patients or survivors in a reasonably large sample [36, 89-94]. A reason for this might be the lack of information about the mechanisms of fatigue and that, currently, there exists no gold standard intervention for the treatment of fatigue [102]. Other reasons might be that AYA cancer survivors can be difficult to reach due to transitions in care and changes of contact information and usually, studies including AYA cancer survivors have lower response rates than other groups [103]. Furthermore, barriers for screening for CRF might also contribute to the lack of intervention studies. More high-quality randomized controlled trials (RCT) are needed to study the effectiveness of the 
physical activity, adventure-based, educational, psychosocial, relaxation and mindfulness, cognitive behavioral therapy, and pharmacological interventions in survivors of CAYA cancers (Table 3). These studies' focus should lie on identifying the most effective interventions for different age groups (pediatric survivors, adolescent survivors, young adult survivors, and adult survivors of CAYA cancers). Evidence from intervention studies in survivors of adult cancers is expected to be transferable to young adult cancer survivors and can be used to guide the design of intervention studies for pediatric and adolescent cancer survivors. Validated fatigue measures, such as the PROMIS Pediatric Fatigue Measure or the PedsQL MFS, should be used to assess CRF in RCTs to reduce bias and increase the comparability of results.

To facilitate dissemination and implementation of this CPG, the evidence and recommendations will be presented directly to clinicians through professional societies and conferences.

Strengths of this CPG are the multidisciplinary and international working group involved in the harmonization process, the evidence-based approach, and the transparency in formulating and grading the recommendations. The international collaboration means a reduction of duplication of effort to develop CPGs and brings together knowledge from different research fields and medical disciplines. A limitation of the recommendations is the gap in the literature regarding the risk of fatigue in survivors over time, and interventions to reduce fatigue in CAYA cancer survivors, as well as the great variability of measures used in the included studies. Research to address these gaps in knowledge should be approached in a systematic, comprehensive manner by sufficiently large single-institution studies, or national and international multicenter collaborative projects.

This surveillance guideline, and the international harmonization initiative that underpins it, aims to improve health outcomes by facilitating more consistent LTFU care for CAYA cancer survivors by improving surveillance, detection, and treatment of fatigue in survivors, as well as promoting strategically planned ongoing research that will inform future guideline updates.

Acknowledgments We thank the survivor representatives Jaap den Hartogh (The Netherlands), Zuzana Tomášiková (Switzerland), and Carina Schneider (Austria) from CCI Europe, and Clarissa Schilstra (Australia) for their critical and valuable appraisal of the recommendations.

Authors' contributions Salome Christen: conceptualization, methodology, software, resources, data curation, validation, formal analysis, investigation, writing - original draft, writing - review and editing, visualization, project administration; Katharina Roser: conceptualization, methodology, software, resources, data curation, validation, formal analysis, investigation, writing - review and editing, visualization; Renée L. Mulder: conceptualization, methodology, resources, data curation, validation, formal analysis, investigation, writing - review and editing, supervision;
Anica Ilic: validation, formal analysis, investigation, writing - review and editing; Hanne C. Lie: validation, formal analysis, investigation, writing - review and editing; Jacqueline J. Loonen: validation, formal analysis, investigation, writing - review and editing; Anneli V. Mellblom: validation, formal analysis, investigation, writing - review and editing; Leontien C.M. Kremer: conceptualization, methodology, resources, data curation, validation, formal analysis, investigation, writing - review and editing, supervision; Melissa M. Hudson: conceptualization, methodology, resources, data curation, writing - review and editing; Louis S. Constine: conceptualization, methodology, resources, data curation, writing - review and editing; Roderick Skinner: conceptualization, methodology, resources, data curation, writing - review and editing; Katrin Scheinemann: conceptualization, methodology, resources, data curation, validation, formal analysis, investigation, writing - review and editing, supervision; Jordan Gilleland Marchak: conceptualization, methodology, resources, data curation, validation, formal analysis, investigation, writing - review and editing, supervision; Gisela Michel: conceptualization, methodology, resources, data curation, validation, formal analysis, investigation, writing - review and editing, visualization, supervision, funding acquisition. All authors approved the final version.

Funding information This work was supported by the Krebsliga Zentralschweiz, the Swiss National Science Foundation (Grant No. 10001C 182129/1 and 100019 153268/1), and the European Union's Seventh Framework Programme for research, technological development, and demonstration, under grant agreement number 257505. The University of Lucerne research committee (FoKo) (https://www.unilu.ch/ en/research/university-of-lucerne-funding/research-committee/) and the Dept Health Science and Medicine of the University of Lucerne support the open access publication.

\section{Compliance with ethical standards}

Conflict of interest The authors declare that they have no conflict of interest.

Disclaimer The funding sources had no role in the design, execution, analyses, interpretation of the data, or decision to submit results of this study.

Open Access This article is licensed under a Creative Commons Attribution 4.0 International License, which permits use, sharing, adaptation, distribution and reproduction in any medium or format, as long as you give appropriate credit to the original author(s) and the source, provide a link to the Creative Commons licence, and indicate if changes were made. The images or other third party material in this article are included in the article's Creative Commons licence, unless indicated otherwise in a credit line to the material. If material is not included in the article's Creative Commons licence and your intended use is not permitted by statutory regulation or exceeds the permitted use, you will need to obtain permission directly from the copyright holder. To view a copy of this licence, visit http://creativecommons.org/licenses/by/4.0/.

\section{References}

1. Smith MA, Altekruse SF, Adamson PC, Reaman GH, Seibel NL. Declining childhood and adolescent cancer mortality. Cancer. 2014;120(16):2497-506. https://doi.org/10.1002/cncr.28748.

2. Gatta G, Zigon G, Capocaccia R, Coebergh JW, Desandes E, Kaatsch $\mathrm{P}$, et al. Survival of European children and young adults 
with cancer diagnosed 1995-2002. Eur J Cancer. 2009;45(6):9921005. https://doi.org/10.1016/j.ejca.2008.11.042.

3. Bosetti C, Bertuccio P, Chatenoud L, Negri E, Levi F, La Vecchia C. Childhood cancer mortality in Europe, 1970-2007. Eur J Cancer. 2010;46(2):384-94. https://doi.org/10.1016/j.ejca.2009. 09.011 .

4. Phillips SM, Padgett LS, Leisenring WM, Stratton KK, Bishop K, Krull KR, et al. Survivors of childhood cancer in the United States: prevalence and burden of morbidity. Cancer Epidemiol Biomark Prev. 2015;24(4):653-63. https://doi.org/10.1158/10559965.EPI-14-1418.

5. Oeffinger KC, Mertens AC, Sklar CA, Kawashima T, Hudson MM, Meadows AT, et al. Chronic health conditions in adult survivors of childhood cancer. N Engl J Med. 2006;355(15):157282. https://doi.org/10.1056/NEJMsa060185.

6. Tai E, Buchanan N, Townsend J, Fairley T, Moore A, Richardson LC. Health status of adolescent and young adult cancer survivors. Cancer. 2012;118(19):4884-91. https://doi.org/10.1002/cncr. 27445.

7. Hudson MM, Ness KK, Gurney JG, Mulrooney DA, Chemaitilly $\mathrm{W}$, Krull KR, et al. Clinical ascertainment of health outcomes among adults treated for childhood cancer. JAMA. 2013;309(22):2371-81. https://doi.org/10.1001/jama.2013.6296.

8. Servaes P, Verhagen C, Bleijenberg G. Fatigue in cancer patients during and after treatment: prevalence, correlates and interventions. Eur J Cancer. 2002;38(1):27-43.

9. Langeveld N, Ubbink M, Smets E, Dutch Late Effects Study G. 'I don't have any energy': the experience of fatigue in young adult survivors of childhood cancer. Eur J Oncol Nurs. 2000;4(1):20-8. https://doi.org/10.1054/ejon.1999.0063.

10. Mock V, Atkinson A, Barsevick A, Cella D, Cimprich B, Cleeland $\mathrm{C}$, et al. NCCN practice guidelines for cancer-related fatigue. Oncology (Williston Park). 2000;14(11A):151-61.

11. Cella D, Davis K, Breitbart W, Curt G, Fatigue C. Cancer-related fatigue: prevalence of proposed diagnostic criteria in a United States sample of cancer survivors. J Clin Oncol. 2001;19(14): 3385-91. https://doi.org/10.1200/JCO.2001.19.14.3385.

12. Bower JE, Ganz PA, Desmond KA, Bernaards C, Rowland JH, Meyerowitz BE, et al. Fatigue in long-term breast carcinoma survivors: a longitudinal investigation. Cancer. 2006;106(4):751-8. https://doi.org/10.1002/cncr.21671.

13. Hamre H, Zeller B, Kanellopoulos A, Kiserud CE, Aakhus S, Lund $\mathrm{MB}$, et al. High prevalence of chronic fatigue in adult long-term survivors of acute lymphoblastic leukemia and lymphoma during childhood and adolescence. J Adolesc Young Adul. 2013;2(1):2-9. https://doi.org/10.1089/jayao.2012.0015.

14. Johannsdottir IM, Hjermstad MJ, Moum T, Wesenberg F, Hjorth $\mathrm{L}$, Schroder H, et al. Increased prevalence of chronic fatigue among survivors of childhood cancers: a population-based study. Pediatr Blood Cancer. 2012;58(3):415-20. https://doi.org/10. 1002/pbc.23111

15. Mulrooney DA, Ness KK, Neglia JP, Whitton JA, Green DM, Zeltzer LK, et al. Fatigue and sleep disturbance in adult survivors of childhood cancer: a report from the childhood cancer survivor study (CCSS). Sleep. 2008;31(2):271-81.

16. Langeveld NE, Grootenhuis MA, Voute PA, de Haan RJ, van den Bos C. No excess fatigue in young adult survivors of childhood cancer. Eur J Cancer. 2003;39(2):204-14.

17. Frederick NN, Kenney L, Vrooman L, Recklitis CJ. Fatigue in adolescent and adult survivors of non-CNS childhood cancer: a report from project REACH. Support Care Cancer. 2016;24(9): 3951-9. https://doi.org/10.1007/s00520-016-3230-2.

18. Meeske KA, Siegel SE, Globe DR, Mack WJ, Bernstein L. Prevalence and correlates of fatigue in long-term survivors of childhood leukemia. J Clin Oncol. 2005;23(24):5501-10. https:// doi.org/10.1200/jco.2005.03.210.
19. Woolf SH, Grol R, Hutchinson A, Eccles M, Grimshaw J. Clinical guidelines: potential benefits, limitations, and harms of clinical guidelines. BMJ. 1999;318(7182):527-30.

20. Grimshaw JM, Russell IT. Effect of clinical guidelines on medical practice: a systematic review of rigorous evaluations. Lancet. 1993;342(8883):1317-22.

21. Essig S, Skinner R, von der Weid NX, Kuehni CE, Michel G. Follow-up programs for childhood cancer survivors in Europe: a questionnaire survey. PLoS One. 2012;7(12):e53201. https://doi. org/10.1371/journal.pone.0053201.

22. Nathan PC, Greenberg ML, Ness KK, Hudson MM, Mertens AC, Mahoney MC, et al. Medical care in long-term survivors of childhood cancer: a report from the childhood cancer survivor study. J Clin Oncol. 2008;26(27):4401-9. https://doi.org/10.1200/JCO. 2008.16.9607.

23. Ebede CC, Jang Y, Escalante CP. Cancer-related fatigue in cancer survivorship. Med Clin North Am. 2017;101(6):1085-97. https:// doi.org/10.1016/j.mena.2017.06.007.

24. Howell D, Keshavarz H, Broadfield L, Hack T, Hamel M, Harth T et al. A Pan Canadian Practice Guideline for Screening, Assessment, and Management of Cancer-Related Fatigue in Adults Version 2-2015. Toronto: Canadian Partnership Against Cancer (Cancer Journey Advisory Group) and the Canadian Association of Psychosocial Oncology. 2015.

25. Children's Oncology Group. Long-Term Follow-Up Guidelines for Survivors of Childhood, Adolescent, and Young Adult Cancers V4.0. 2013. http://www.survivorshipguidelines.org/. Accessed 28 July 2016.

26. Dutch Childhood Oncology Group. Guidelines for follow-up in survivors of childhood cancer 5 years after diagnosis. SKION, Den Haag/Amsterdam; the Netherlands: 2010. Available online: https://www.skion.nl/workspace/uploads/vertaling-richtlijnLATER-versie-final-okt-2014 2.pdf2010.

27. Scottish Intercollegiate Guidelines Network (SIGN). Long term follow up of survivors of childhood cancer. A national clinical guideline. 2013. http://www.sign.ac.uk/pdf/sign76.pdf. Accessed 28 July 2016.

28. United Kingdom Children's Cancer Study Group Late Effects Group. Therapy Based Long Term Follow Up - Practice Statement: 2005. Available online: http://www.uhb.nhs.uk/ Downloads/pdf/CancerPbTherapyBasedLongTermFollowUp. pdf2005.

29. Kremer LC, Mulder RL, Oeffinger KC, Bhatia S, Landier W, Levitt $\mathrm{G}$, et al. A worldwide collaboration to harmonize guidelines for the long-term follow-up of childhood and young adult cancer survivors: a report from the International Late Effects of Childhood Cancer Guideline Harmonization Group. Pediatr Blood Cancer. 2013;60(4):543-9. https://doi.org/10.1002/pbc. 24445.

30. Atkins D, Best D, Briss PA, Eccles M, Falck-Ytter Y, Flottorp S, et al. Grading quality of evidence and strength of recommendations. BMJ. 2004;328(7454):1490. https://doi.org/10.1136/bmj. 328.7454.1490.

31. Gibbons RJ, Smith S, Antman E, American College of C, American Heart A. American College of Cardiology/American Heart Association clinical practice guidelines: part I: where do they come from? Circulation. 2003;107(23):2979-86. https:// doi.org/10.1161/01.CIR.0000063682.20730.A5.

32. Adams MJ, Lipsitz SR, Colan SD, Tarbell NJ, Treves ST, Diller L, et al. Cardiovascular status in long-term survivors of Hodgkin's disease treated with chest radiotherapy. J Clin Oncol. 2004;22(15):3139-48. https://doi.org/10.1200/jco.2004.09.109.

33. Aksnes LH, Hall KS, Jebsen N, Fossa SD, Dahl AA. Young survivors of malignant bone tumours in the extremities: a comparative study of quality of life, fatigue and mental distress. Support 
Care Cancer. 2007;15(9):1087-96. https://doi.org/10.1007/ s00520-007-0227-x.

34. Berg C, Neufeld P, Harvey J, Downes A, Hayashi RJ. Late effects of childhood cancer, participation, and quality of life of adolescents. Otjr-Occup Particip Health. 2009;29(3):116-24. https://doi. org/10.3928/15394492-20090611-04.

35. Berg C, Hayashi RJ. Participation and self-management strategies of young adult childhood cancer survivors. Otjr-Occup Particip Health. 2013;33(1):21-30. https://doi.org/10.3928/1539449220120607-01.

36. Blaauwbroek R, Bouma MJ, Tuinier W, Groenier KH, de Greef $\mathrm{MH}$, Meyboom-de Jong B, et al. The effect of exercise counselling with feedback from a pedometer on fatigue in adult survivors of childhood cancer: a pilot study. Support Care Cancer. 2009;17(8): 1041-8. https://doi.org/10.1007/s00520-008-0533-y.

37. Brand SR, Chordas C, Liptak C, Manley P, Recklitis C. Screening for fatigue in adolescent and young adult pediatric brain tumor survivors: accuracy of a single-item screening measure. Support Care Cancer. 2016;24(8):3581-7. https://doi.org/10.1007/s00520016-3150-1.

38. Clanton NR, Klosky JL, Li C, Jain N, Srivastava DK, Mulrooney $\mathrm{D}$, et al. Fatigue, vitality, sleep, and neurocognitive functioning in adult survivors of childhood cancer: a report from the Childhood Cancer Survivor Study. Cancer. 2011;117(11):2559-68. https:// doi.org/10.1002/cncr.25797.

39. Daniel L, Kazak AE, Li Y, Hobbie W, Ginsberg J, Butler E, et al. Relationship between sleep problems and psychological outcomes in adolescent and young adult cancer survivors and controls. Support Care Cancer. 2016;24(2):539-46. https://doi.org/10. 1007/s00520-015-2798-2.

40. Enskar K, von Essen L. Prevalence of aspects of distress, coping, support and care among adolescents and young adults undergoing and being off cancer treatment. Eur J Oncol Nurs. 2007;11(5): 400-8. https://doi.org/10.1016/j.ejon.2007.01.003.

41. Geenen MM, Cardous-Ubbink MC, Kremer LCM, Van Den Bos C, Van Der Pal HJH, Heinen RC, et al. Medical assessment of adverse health outcomes in long-term survivors of childhood cancer. J Am Med Assoc. 2007;297(24):2705-15. https://doi.org/10. 1001/jama.297.24.2705.

42. Hamre H, Zeller B, Kanellopoulos A, Ruud E, Fossa SD, Loge $\mathrm{JH}$, et al. Serum cytokines and chronic fatigue in adults surviving after childhood leukemia and lymphoma. Brain Behav Immun. 2013;30:80-7. https://doi.org/10.1016/j.bbi.2013.01.006.

43. Kanellopoulos A, Hamre HM, Dahl AA, Fossa SD, Ruud E. Factors associated with poor quality of life in survivors of childhood acute lymphoblastic leukemia and lymphoma. Pediatr Blood Cancer. 2013;60(5):849-55. https://doi.org/10.1002/pbc.24375.

44. Kenney LB, Nancarrow CM, Najita J, Vrooman LM, Rothwell M, Recklitis C, et al. Health status of the oldest adult survivors of cancer during childhood. Cancer. 2010;116(2):497-505. https:// doi.org/10.1002/cncr.24718.

45. Khan RB, Hudson MM, Ledet DS, Morris EB, Pui CH, Howard $\mathrm{SC}$, et al. Neurologic morbidity and quality of life in survivors of childhood acute lymphoblastic leukemia: a prospective crosssectional study. J Cancer Surviv : research and practice. 2014;8(4):688-96. https://doi.org/10.1007/s11764-014-0375-1.

46. Manley PE, McKendrick K, McGillicudy M, Chi SN, Kieran MW, Cohen LE, et al. Sleep dysfunction in long term survivors of craniopharyngioma. J Neuro-Oncol. 2012;108(3):543-9. https://doi.org/10.1007/s11060-012-0859-7.

47. McClellan W, Klemp JR, Krebill H, Ryan R, Nelson EL, Panicker $\mathrm{J}$, et al. Understanding the functional late effects and informational needs of adult survivors of childhood cancer. Oncol Nurs Forum. 2013;40(3):254-62. https://doi.org/10.1188/13.onf.254-262.

48. Yi J, Kim MA, Tian T. Perceived long-term and physical health problems after cancer: adolescent and young adult survivors of childhood cancer in Korea. Eur J Oncol Nurs. 2014;18(2):14550. https://doi.org/10.1016/j.ejon.2013.11.006.

49. Fortmann J, Fisher A, Hough R, Gregory A, Pugh G. Sleep quality, fatigue, and quality of life among teenage and young adult cancer survivors. J Adolesc Young Adult Oncol. 2018;7(4):46571. https://doi.org/10.1089/jayao.2018.0004.

50. Rach AM, Crabtree VM, Brinkman TM, Zeltzer L, Marchak JG, Srivastava D, et al. Predictors of fatigue and poor sleep in adult survivors of childhood Hodgkin's lymphoma: a report from the Childhood Cancer Survivor Study. J Cancer Surviv : research and practice. 2017;11(2):256-63. https://doi.org/10.1007/s11764016-0583-y.

51. Johannsdottir IMR, Hamre H, Fossa SD, Loge JH, Drolsum L, Lund $\mathrm{MB}$, et al. Adverse health outcomes and associations with self-reported general health in childhood lymphoma survivors. J Adolesc Young Adult Oncol. 2017;6(3):470-6. https://doi.org/10. 1089/jayao.2017.0018.

52. Spathis A, Hatcher H, Booth S, Gibson F, Stone P, Abbas L, et al. Cancer-related fatigue in adolescents and young adults after cancer treatment: persistent and poorly managed. J Adolesc Young Adult Oncol. 2017;6(3):489-93. https://doi.org/10.1089/jayao. 2017.0037.

53. Karimi M, Cox AD, White SV, Karlson CW. Fatigue, physical and functional mobility, and obesity in pediatric cancer survivors. Cancer Nurs. 2019. https://doi.org/10.1097/NCC. 0000000000000712 .

54. Arpaci T, Kilicarslan TE. Assessment of problems and symptoms in survivors of childhood acute lymphoblastic leukaemia. Eur J Cancer Care (Engl). 2016;25(6):1034 43. https://doi.org/10.1111/ ecc. 12561 .

55. Calaminus G, Dorffel W, Baust K, Teske C, Riepenhausen M, Bramswig J, et al. Quality of life in long-term survivors following treatment for Hodgkin's disease during childhood and adolescence in the German multicentre studies between 1978 and 2002. Support Care Cancer. 2014;22(6):1519-29. https://doi.org/ 10.1007/s00520-013-2114-y.

56. de Ruiter MA, Schouten-van Meeteren AYN, van Vuurden DG, Maurice-Stam H, Gidding C, Beek LR, et al. Psychosocial profile of pediatric brain tumor survivors with neurocognitive complaints. Qual Life Res Int J Qual Life Asp Treat Care Rehab. 2016;25(2): 435-46. https://doi.org/10.1007/s11136-015-1091-7.

57. Gordijn MS, van Litsenburg RR, Gemke RJ, Huisman J, Bierings $\mathrm{MB}$, Hoogerbrugge PM, et al. Sleep, fatigue, depression, and quality of life in survivors of childhood acute lymphoblastic leukemia. Pediatr Blood Cancer. 2013;60(3):479-85. https://doi.org/ 10.1002/pbc.24261.

58. Ho KY, Li WH, Lam KW, Chui SY, Chan CF. Psychometric properties of the Chinese version of the fatigue scale-adolescent. BMC Cancer. 2015;15:938. https://doi.org/10.1186/s12885-0151945-y.

59. Korinthenberg R, Neuburger D, Nikkhah G, Teske C, Schnabel K, Calaminus G. Assessing quality of life in long-term survivors after 125I brachytherapy for low-grade glioma in childhood. Neuropediatrics. 2011;42(3):110-5. https://doi.org/10.1055/s0031-1283111.

60. Mort S, Lahteenmaki PM, Matomaki J, Salmi TT, Salantera S. Fatigue in young survivors of extracranial childhood cancer: a Finnish nationwide survey. Oncol Nurs Forum. 2011;38(6): E445-54. https://doi.org/10.1188/11.onf.e445-e454.

61. Nagai A, Zou N, Kubota M, Kojima C, Adachi S, Usami I, et al. Fatigue in survivors of childhood acute lymphoblastic and myeloid leukemia in Japan. Pediatr Int : official journal of the Japan Pediatric Society. 2012;54(2):272-6. https://doi.org/10.1111/j. 1442-200X.2011.03530.x. 
62. Vannatta K, Gartstein MA, Short A, Noll RB. A controlled study of peer relationships of children surviving brain tumors: teacher, peer, and self ratings. J Pediatr Psychol. 1998;23(5):279-87.

63. Zeltzer LK, Chen E, Weiss R, Guo MD, Robison LL, Meadows AT, et al. Comparison of psychologic outcome in adult survivors of childhood acute lymphoblastic leukemia versus sibling controls: a cooperative Children's Cancer Group and National Institutes of Health study. J Clin Oncol. 1997;15(2):547-56.

64. Nies M, Klein Hesselink MS, Huizinga GA, Sulkers E, Brouwers $\mathrm{AH}$, Burgerhof JGM, et al. Long-term quality of life in adult survivors of pediatric differentiated thyroid carcinoma. J Clin Endocrinol Metab. 2017;102(4):1218-26. https://doi.org/10. 1210/jc.2016-2246.

65. Cheung YT, Brinkman TM, Mulrooney DA, Mzayek Y, Liu W, Banerjee $\mathrm{P}$, et al. Impact of sleep, fatigue, and systemic inflammation on neurocognitive and behavioral outcomes in long-term survivors of childhood acute lymphoblastic leukemia. Cancer. 2017;123(17):3410-9. https://doi.org/10.1002/cncr.30742.

66. Graef DM, Phipps S, Parris KR, Martin-Elbahesh K, Huang L, Zhang $\mathrm{H}$, et al. Sleepiness, fatigue, behavioral functioning, and quality of life in survivors of childhood hematopoietic stem cell transplant. J Pediatr Psychol. 2016;41(6):600-9. https://doi.org/ 10.1093/jpepsy/jsw011.

67. Barrera M, Teall T, Barr R, Silva M, Greenberg M. Health related quality of life in adolescent and young adult survivors of lower extremity bone tumors. Pediatr Blood Cancer. 2012;58(2):26573. https://doi.org/10.1002/pbc.23017.

68. Sato I, Higuchi A, Yanagisawa T, Murayama S, Kumabe T, Sugiyama K, et al. Impact of late effects on health-related quality of life in survivors of pediatric brain tumors: motility disturbance of limb(s), seizure, ocular/visual impairment, endocrine abnormality, and higher brain dysfunction. Cancer Nurs. 2014;37(6):E1e14. https://doi.org/10.1097/ncc.0000000000000110.

69. Sterkenburg AS, Hoffmann A, Gebhardt U, Warmuth-Metz M, Daubenbuchel AM, Muller HL. Survival, hypothalamic obesity, and neuropsychological/psychosocial status after childhood-onset craniopharyngioma: newly reported long-term outcomes. Neurooncology. 2015;17(7):1029-38. https://doi.org/10.1093/neuonc/ nov044.

70. Zeller B, Loge JH, Kanellopoulos A, Hamre H, Wyller VB, Ruud E. Chronic fatigue in long-term survivors of childhood lymphomas and leukemia: persistence and associated clinical factors. $\mathrm{J}$ Pediatr Hematol Oncol. 2014;36(6):438-44. https://doi.org/10. 1097/mph.0000000000000051.

71. Lowe K, Escoffery C, Mertens AC, Berg CJ. Distinct health behavior and psychosocial profiles of young adult survivors of childhood cancers: a mixed methods study. J Cancer Surviv : research and practice. 2016;10:619-32. https://doi.org/10.1007/s11764015-0508-1.

72. Zebrack BJ, Chesler MA. Quality of life in childhood cancer survivors. Psychooncology. 2002;11(2):132-41.

73. Macpherson CF, Hooke MC, Friedman DL, Campbell K, Withycombe J, Schwartz CL, et al. Exercise and Fatigue in adolescent and young adult survivors of Hodgkin lymphoma: a report from the Children's Oncology Group. J Adolesc Young Adult Oncol. 2015;4(3):137-40. https://doi.org/10.1089/jayao.2015. 0013.

74. Tomlinson D, Hinds PS, Ethier MC, Ness KK, Zupanec S, Sung L. Psychometric properties of instruments used to measure fatigue in children and adolescents with cancer: a systematic review. J Pain Symptom Manag. 2013;45(1):83-91. https://doi.org/10. 1016/j.jpainsymman.2012.02.010.

75. Ho KY, Li WH, Lam KW, Chiu SY, Chan CF. The psychometric properties of the Chinese version of the Fatigue scale for children. Cancer Nurs. 2016;39(5):341-8. https://doi.org/10.1097/NCC. 0000000000000297.
76. Gerceker GO, Yilmaz HB. Reliability and validity of Turkish versions of the child, parent and staff cancer fatigue scales. Asian Pac J Cancer Prev. 2012;13(7):3135-41.

77. Mandrell BN, Yang J, Hooke MC, Wang C, Gattuso JS, Hockenberry M, et al. Psychometric and clinical assessment of the 13-item reduced version of the fatigue scale-adolescent instrument. J Pediatr Oncol Nurs. 2011;28(5):287-94. https://doi.org/ $10.1177 / 1043454211418667$.

78. Hinds PS, Hockenberry M, Tong X, Rai SN, Gattuso JS, McCarthy K, et al. Validity and reliability of a new instrument to measure cancer-related fatigue in adolescents. J Pain Symptom Manag. 2007;34(6):607-18. https://doi.org/10.1016/j. jpainsymman.2007.01.009.

79. Al-Gamal E, Long T. The psychometric properties of an Arabic version of the PedsQL multidimensional fatigue scale tested for children with cancer. Compr Child Adolesc Nurs. 2017;40(3): 188-99. https://doi.org/10.1080/24694193.2017.1316791.

80. Nascimento LC, Rodrigues Nunes MD, Rocha EL, Bomfim EO, Floria-Santos M, dos Santos CB, et al. High validity and reliability of the PedsQL (TM) multidimensional fatigue scale for Brazilian children with cancer. J Pediatr Oncol Nurs. 2015;32(1):57-64. https://doi.org/10.1177/1043454214554656.

81. Robert RS, Paxton RJ, Palla SL, Yang G, Askins MA, Joy SE, et al. Feasibility, reliability, and validity of the pediatric quality of life inventory generic core scales, cancer module, and multidimensional fatigue scale in long-term adult survivors of pediatric cancer. Pediatr Blood Cancer. 2012;59(4):703-7. https://doi.org/10. $1002 /$ pbc.24099.

82. Hinds PS, Wang J, Cheng YI, Stern E, Waldron M, Gross H, et al. PROMIS pediatric measures validated in a longitudinal study design in pediatric oncology. Pediatr Blood Cancer. 2019;66(5): e27606. https://doi.org/10.1002/pbc.27606.

83. Macpherson CF, Wang J, DeWalt DA, Stern ED, Jacobs S, Hinds PS. Comparison of legacy fatigue measures with the PROMIS pediatric fatigue short form. Oncol Nurs Forum. 2018;45(1): 106-14. https://doi.org/10.1188/18.ONF.106-114.

84. Lai JS, Beaumont JL, Nowinski CJ, Cella D, Hartsell WF, HanChih Chang J, et al. Computerized adaptive testing in pediatric brain tumor clinics. J Pain Symptom Manag. 2017;54(3):289-97. https://doi.org/10.1016/j.jpainsymman.2017.05.008.

85. Hinds PS, Nuss SL, Ruccione KS, Withycombe JS, Jacobs S, DeLuca H, et al. PROMIS pediatric measures in pediatric oncology: valid and clinically feasible indicators of patient-reported outcomes. Pediatr Blood Cancer. 2013;60(3):402-8. https://doi. org/10.1002/pbc.24233.

86. Bektas M, Kudubes AA. Developing scales for the assessment of fatigue in Turkish pediatric oncology patients aged 13-18 and their parents. Asian Pac J Cancer Prev. 2014;15(22):9891-8.

87. Kudubes AA, Bektas M, Ugur O. Developing a scale for the assessment of fatigue in pediatric oncology patients aged 7-12 for children and parents. Asian Pac J Cancer Prev. 2014;15(23): 10199-207.

88. Baptista RL, Biasoli I, Scheliga A, Soares A, Brabo E, Morais JC, et al. Psychometric properties of the multidimensional fatigue inventory in Brazilian Hodgkin's lymphoma survivors. J Pain Symptom Manag. 2012;44(6):908-15. https://doi.org/10.1016/j. jpainsymman.2011.12.275.

89. Boonstra A, Gielissen M, van Dulmen-den Broeder E, Blijlevens N, Knoop H, Loonen J. Cognitive behavior therapy for persistent severe fatigue in childhood cancer survivors: a pilot study. $\mathrm{J}$ Pediatr Hematol Oncol. 2019;41(4):313-8. https://doi.org/10. 1097/MPH.0000000000001345.

90. Li WHC, Ho KY, Lam KKW, Lam HS, Chui SY, Chan GCF, et al. Adventure-based training to promote physical activity and reduce fatigue among childhood cancer survivors: a randomized 
controlled trial. Int J Nurs Stud. 2018;83:65-74. https://doi.org/10. 1016/j.ijnurstu.2018.04.007.

91. Kudubes AA, Bektas M, Mutafoglu K. The effect of Fatigue-related education on pediatric oncology patients' fatigue and quality of life. $\mathrm{J}$ Cancer Educ. 2018. https://doi.org/10.1007/s13187-018-1419-4.

92. Nunes MDR, Bomfim E, Olson K, Lopes-Junior LC, SilvaRodrigues FM, Garcia de Lima RA, et al. Interventions minimizing fatigue in children/adolescents with cancer: an integrative review. J Child Health Care. 2018;22(2):186-204. https://doi.org/ $10.1177 / 1367493517752498$.

93. Baumann FT, Bloch W, Beulertz J. Clinical exercise interventions in pediatric oncology: a systematic review. Pediatr Res. 2013;74(4):366-74. https://doi.org/10.1038/pr.2013.123.

94. Chang C-W, Mu P-F, Jou S-T, Wong T-T, Chen Y-C. Systematic review and meta-analysis of nonpharmacological interventions for fatigue in children and adolescents with cancer. Worldviews EvidBased Nurs. 2013;10(4):208-17. https://doi.org/10.1111/wvn.12007.

95. Robinson PD, Oberoi S, Tomlinson D, Duong N, Davis H, Cataudella D, et al. Management of fatigue in children and adolescents with cancer and in paediatric recipients of haemopoietic stem-cell transplants: a clinical practice guideline. Lancet Child Adolesc Health. 2018;2(5):371-8. https://doi.org/10.1016/S23524642(18)30059-2.

96. Armenian SH, Hudson MM, Mulder RL, Chen MH, Constine LS, Dwyer M, et al. Recommendations for cardiomyopathy surveillance for survivors of childhood cancer: a report from the International Late Effects of Childhood Cancer Guideline Harmonization Group. Lancet Oncol. 2015;16(3):e123-36. https://doi.org/10.1016/S1470-2045(14)70409-7.

97. Bower JE, Bak K, Berger A, Breitbart W, Escalante CP, Ganz PA, et al. Screening, assessment, and management of fatigue in adult survivors of cancer: an American Society of Clinical oncology clinical practice guideline adaptation. J Clin Oncol. 2014;32(17): 1840-50. https://doi.org/10.1200/JCO.2013.53.4495.

98. Christen S, Vetsch J, Mader L, Dehler S, Korol D, Kuehni C, et al. Preferences for the organization of long-term follow-up in adolescent and young adult cancer survivors. Support Care Cancer. 2016;24(8): 3425-36. https://doi.org/10.1007/s00520-016-3157-7.

99. Vetsch J, Rueegg CS, Mader L, Bergstraesser E, Rischewski J, Kuehni CE, et al. Follow-up care of young childhood cancer survivors: attendance and parental involvement. Support Care Cancer. 2016;24(7):3127-38. https://doi.org/10.1007/s00520-016-3121-6.

100. Szalda D, Pierce L, Hobbie W, Ginsberg JP, Brumley L, Wasik M, et al. Engagement and experience with cancer-related follow-up care among young adult survivors of childhood cancer after transfer to adult care. J Cancer Surviv : research and practice. 2016;10(2):342-50. https://doi.org/10.1007/s11764-015-0480-9.

101. Barsevick AM, Irwin MR, Hinds P, Miller A, Berger A, Jacobsen $\mathrm{P}$, et al. Recommendations for high-priority research on cancerrelated fatigue in children and adults. J Natl Cancer Inst. 2013;105(19):1432-40. https://doi.org/10.1093/jnci/djt242.

102. Bower JE. Cancer-related fatigue-mechanisms, risk factors, and treatments. Nat Rev Clin Oncol. 2014;11(10):597-609. https:// doi.org/10.1038/nrclinonc.2014.127.

103. Harlan LC, Lynch CF, Keegan TH, Hamilton AS, Wu XC, Kato I, et al. Recruitment and follow-up of adolescent and young adult cancer survivors: the AYA HOPE study. J Cancer Surviv : research and practice. 2011;5(3):305-14. https://doi.org/10.1007/s11764-0110173-y.

Publisher's note Springer Nature remains neutral with regard to jurisdictional claims in published maps and institutional affiliations.

\section{Affiliations}

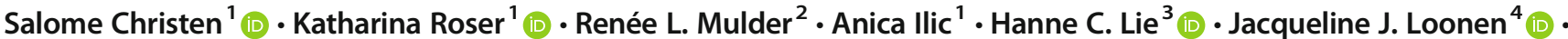 Anneli V. Mellblom ${ }^{3} \cdot$ Leontien C. M. Kremer ${ }^{2}$ - Melissa M. Hudson ${ }^{5}$ (D) Louis S. Constine $^{6} \cdot$ Roderick Skinner $^{7}$ (D) Katrin Scheinemann ${ }^{8,9,10}$ • Jordan Gilleland Marchak ${ }^{11,12}$. Gisela Michel ${ }^{1}$ (i) $\cdot$ on behalf of the IGHG psychological late effects group}

\author{
Salome Christen \\ salome.christen@unilu.ch \\ Katharina Roser \\ katharina.roser@unilu.ch \\ Renée L. Mulder \\ renee.oud-mulder@prinsesmaximacentrum.nl \\ Anica Ilic \\ anica.ilic@unilu.ch \\ Hanne C. Lie \\ h.c.lie@medisin.uio.no \\ Jacqueline J. Loonen \\ jacqueline.loonen@radboudumc.nl \\ Anneli V. Mellblom \\ anneli.mellblom@medisin.uio.no
}

\author{
Leontien C. M. Kremer \\ 1.c.m.kremer@prinsesmaximacentrum.nl \\ Melissa M. Hudson \\ melissa.hudson@stjude.org \\ Louis S. Constine \\ louis_constine@urmc.rochester.edu \\ Roderick Skinner \\ roderick.skinner@newcastle.ac.uk \\ Katrin Scheinemann \\ katrin.scheinemann@ksa.ch \\ Jordan Gilleland Marchak \\ jgillel@emory.edu
}

1 Department of Health Sciences and Medicine, University of Lucerne, Lucerne, Switzerland
2 Princess Máxima Center for Pediatric Oncology, Utrecht, The Netherlands 
3 Department of Behavioural Sciences in Medicine, Institute of Basic Medical Sciences, Faculty of Medicine, University of Oslo, Oslo, Norway

4 Department of Hematology, Radboud University Medical Center, Nijmegen, The Netherlands

5 Departments of Epidemiology and Cancer Control, and Oncology, St. Jude Children's Research Hospital, Memphis, USA

6 Departments of Radiation Oncology and Pediatrics, University of Rochester Medical Center, Rochester, USA

7 Department of Paediatric and Adolescent Haematology/Oncology, Great North Children's Hospital and Newcastle University Centre for Cancer, Newcastle upon Tyne, UK
Division of Hematology/Oncology, Department of Pediatrics, Kantonsspital Aarau, Aarau, Switzerland

9 Division of Hematology/Oncology, University Children's Hospital Basel and University of Basel, Basel, Switzerland

10 Department of Pediatrics, McMaster Children's Hospital and McMaster University, Hamilton, Canada

11 Aflac Cancer and Blood Disorders Center, Children's Healthcare of Atlanta, Atlanta, GA, USA

12 Department of Pediatrics, Emory University School of Medicine, Atlanta, GA, USA 